\title{
Seasonal changes in social networks of giraffe
}

Tanja E Wolf ${ }^{1,2}$, Axel-Cyrille Ngonga Ngomo ${ }^{3,4}$, Nigel C Bennett ${ }^{5,6}$, Richard Burroughs $^{7}$, and Andre Ganswindt ${ }^{1,5}$

${ }^{1}$ Endocrine Research Laboratory, Department of Anatomy and Physiology, Faculty of Veterinary Science, University of Pretoria, Onderstepoort 0110, South Africa

${ }^{2}$ Department of Animal, Wildlife and Grassland Sciences, Faculty of Natural and Agricultural Sciences, University of the Free State, Bloemfontein 9300, South Africa

${ }^{3}$ AKSW Research Group, University of Leipzig, Leipzig, Germany

${ }^{4}$ Data Science Group, Department of Computer Science, University of Paderborn, Germany

${ }^{5}$ Mammal Research Institute, Department of Zoology and Entomology, Faculty of Natural and Agricultural Sciences, University of Pretoria, Pretoria 0028, South Africa

${ }^{6}$ South African Research Chair of Mammal Behavioural Ecology and Physiology, Department of Zoology and Entomology, Faculty of Natural and Agricultural Sciences, University of Pretoria, Pretoria 0028, South Africa

${ }^{7}$ Centre of Veterinary Wildlife Studies, Faculty of Veterinary Science, University of Pretoria, Onderstepoort 0110, South Africa

Corresponding author: Andre Ganswindt, University of Pretoria, Faculty of Veterinary Science, Soutpan Road, 0110 Onderstepoort, Pretoria, South Africa. Email: aganswindt@zoology.up.ac.za 
Short title: Seasonal changes in social networks of giraffe 


\section{Abstract}

Fission-fusion social societies allow animals to respond in a flexible manner to environmental changes by adapting the size and composition of a group. Although group members change frequently in these systems, associations with preferred partners may be found. In this study, we examined the grouping patterns of a population of 80 individual giraffes in a fenced South African game reserve over a 12month period. Using social network analyses as a tool to evaluate observed associations, we subsequently analysed both sex- and season-related grouping patterns within the study population. Mixed sex groups represented $49 \%$ of all groups observed, and although overall group composition distribution did not differ significantly between seasons, the number of encountered single females decreased by $50 \%$, whereas the number of multi-male groups increased by over $50 \%$ in winter. Overall average group size did not differ significantly between seasons, but significantly larger multi-female and multi-male groups were seen in winter. Within the social network, two distinct clusters were found in summer, with the population more divided in winter, with five distinct clusters emerging. The strongest ties (highest HWIGs) were found between adult females. Our study revealed that giraffes do not only live in a highly flexible social fission-fusion system, but also show seasonal patterns of grouping.

Key Words: Giraffa camelopardalis giraffa, social networks, group structure, season 


\section{Introduction}

Living in a group has many advantages, in particular the enhanced detection of predators or the access to mating partners and food resources. However, these advantages have to be weighed up against the costs related to living in a group such as competition for resources and mates (Alexander, 1974; Rubenstein, 1986). Fission-fusion social societies are characterized by the splitting and reunion of subgroups within a larger social network (Aureli et al., 2008), which allow individuals to respond flexibly to environmental changes and challenges by adapting their group sizes (Van der Waal et al., 2014).

Although in fission-fusion societies, associations are often thought to be generally weak, animals may show preferences for certain individuals (Godde et al., 2015). Such developing social networks have an influence on the behaviour of the animals involved, for example about mate choice, cooperative behaviour, and predator avoidance strategies (Shorrocks \& Croft, 2009). Fission-fusion societies are found in a variety of mammalian species, particularly those with distinct flexible grouping patterns as observed in some ungulates, like Grevy's zebras (Equus grevyi) (Sundaresan et al., 2007), or African buffalos (Syncerus caffer) (Cross, Lloyd-Smith \& Getz, 2005). Giraffe group compositions are highly flexible and frequently change on a daily basis (Pratt \& Anderson, 1985; Bercovitch \& Berry, 2009). Recent research has proposed that female giraffes have social preferences, which appear to be influenced by seasonal changes in food resources, availability of conspecifics and relatedness (Bercovitch \& Berry, 2013; Carter et al., 2013b). Adult male giraffes on the other hand, show a different grouping preference compared to females (Bercovitch \& Berry, 2015), which reflects a wider pattern. Such sex-related differences have also been observed in fission-fusion societies of other species 
(Aureli et al., 2008). Group composition also seems to be a more important factor than group size when it comes to vigilance behaviour in giraffes (Cameron \& du Toit, 2005). The presence of larger males appears to lead to an increase in scanning behaviour in other males, whereas females increased their vigilance when conspecifics, especially adult bulls, were nearby (Cameron \& du Toit, 2005).

In this study, we examined the grouping patterns of giraffes (Giraffa camelopardalis giraffa) during the different seasons using network analyses. Social network analysis allows the detection of clusters of individuals within the larger population that interact more frequently with each other (Van der Waal et al., 2014). The underlying regulatory mechanisms of such networks have implications on information transfer, e.g. about food availabilities, finding a mating partner, as well as far more reaching parameters such as gene flow.

\section{Methods}

Data were collected at a private game reserve, a $74 \mathrm{~km}^{2}$ fenced area in KwazuluNatal, South Africa. The reserve mainly comprises of acacia and marula woodland (Vachellia sp., Senegalia $s p$ and Sclerocarya birrea) as well as mixed acacia woodland (mixed Acacia sp.). The wet season, with an average rainfall of 400-600 $\mathrm{mm}$ per annum, occurs during the southern hemisphere summer months (Shannon et al., 2006a). The winter months are a dry period with almost no rainfall. Leopard (Panthera pardus) and hyaena (Crocuta crocuta) are present in the reserve. Lion (Panthera leo) consider even adult giraffes as a prey base, but are not present in the reserve, thus we expect the predation risk for our focal population to be low. A giraffe population comprising of 80 individuals ( 27 males, 41 females, and 12 infants of 
unknown sex) was observed for a period of 12 months (Nov 2014 - Oct 2015), with seasons defined as summer (October to March) and winter (April to September). Giraffes were individually identified by their unique pelage pattern. Age classes were defined and described according to Langman (1977), with infants younger than 3 months and still accompanied by their mothers, juveniles $<1.5$ years, sub-adults $<4$ years, and adult fully grown individuals $>4$ years. A group was defined as at least two individuals that were foraging and moving together during the observation, with a distance between group members usually smaller than between groups (Carter et al., 2013a, 2013b). To analyse the social composition of encountered groups, single individuals were included into the analyses (see table 1). All individuals seen in a group were considered associated with each other following the 'gambit of the group' definition of association (Whitehead \& Dufault, 1999). Six days per week, we used the existing road network within the reserve to locate giraffes. Roads were chosen randomly and all roads were followed at least once a week between dawn and dusk. The majority of groups were encountered during the morning and early afternoon hours and were followed up to 4 hours. When a group of giraffes was encountered, group members were initially identified and recorded, as well as whenever one or more animals joined the original group and joined in the same activity, or were engaged in social contact with at least one of the group members. Similarly, group composition was noted once a group member left the group, which was defined as an individual seen moving away from the rest of the group and not re-joining when the group was moving on.

Dependent infants and juveniles were excluded from all network analyses as they were assumed to join the same groups as their mothers. We used an association index to build our networks. As individuals are more likely to be identified when not 
associated and both members of a dyad are not sampled in each sampling period, association indices between dyads of giraffes were calculated using the half-weight index $(\mathrm{HWI})$, which has been shown to reliably reflect association patterns in wild giraffes and takes into account the number of sightings per individual (Cairns \& Schwager, 1987; Carter et al., 2013b). We also controlled for an individual's gregariousness using the HWIG (half-weight index gregariousness corrected) (Godde et al. 2013, Godde, Côté \& Réale, 2015). Only individuals observed for more than six times during the study period $(n=63)$ were included in the analyses to maximize the chance of capturing all possible associations of an individual and to minimize the chance for false null associations between pairs that were not regularly sighted (mean number of sightings per individual: 44 times (range: 6 - 79)) (Frère et al., 2010; Carter et al., 2013b). HWIG was estimated using the program SOCPROG 2.6 (Whitehead, 2009). To analyse the similarity of the HWIG results, the cosine similarity of the distribution of the results were computed. The parameter-free BorderFlow algorithm was used to cluster the graph generated by the HWIG (Ngonga Ngomo \& Schumacher, 2009). Association indices between individuals of the same cluster are generally higher than indices between individuals of different clusters. The number of clusters is an indicator on how socially fragmented the population is.

A Welch Two Sample t-test and Pearson's Chi-squared test were used to compare differences in mean group size and group composition over seasons. To determine differences in HWIGs between males and females and to compare different seasons, a Wilcoxon Rank Sum Test was used. Parametric and non-parametric tests were done using R, version 3.0.2 (R Core Team, 2013). 


\section{Results}

Over the whole study period mixed sex groups represented $49 \%(n=350)$ of all groups observed, multi-female groups were encountered in $20 \%(n=140)$ of the cases, and multi-male groups in $15 \%(n=105)$. Single females were observed in only $6 \%(n=46)$ of the encounters, while single males only $10 \%(n=74)$. Although overall group composition distribution did not differ significantly between seasons ( $x 2$ $=20, \mathrm{df}=16, p=0.2202)$, the number of encountered single females decreased by $50 \%$ during the dry season. Contrary, the number of observed multi-male groups increased by over $50 \%$ in the dry season. However, the number of mixed sex and multi-female groups observed, as well as the number of observed single males, remained almost unchanged between the seasons (see table 1).

The mean group size over the whole 12 month study period for all group types was 7.3 individuals (range $1-25, \mathrm{~N}=715$ groups). Overall average group size did not differ significantly between seasons $(t=-0.7819$, $d f=707.559, p=0.435)$, with a mean group size of 7.1 in the wet season (range $1-25, N=380$ groups) and 7.5 in the dry season (range 1-25, $\mathrm{N}=335$ groups). Interestingly, we found differences in group sizes when looking at specific group compositions, with significantly larger multifemale and multi-male groups during the dry season (see table 1).

The mean association indices (HWIG) for male-male associations in the wet season was 1.05 (range $0.96-1.20$ ) and 1.25 in the dry season (range $0.78-2.43$ ). Mean HWIGs for female-female associations were 1.04 in the wet season (range 0.91 1.15) and 1.12 in the dry season (range $0.79-1.63$ ). Although the overall association indices seemed to be higher in the dry season, no statistically significant difference of mean HWIGs was found between the different seasons $(W=325, p=$ 0.808 for males; $\mathrm{W}=439.5, \mathrm{p}=0.386$ for females). Similarly, we found no significant 
differences in wet $(W=435, p=0.642)$ and dry season $(W=324, p=0.833)$ when comparing mean male and female HWIGs.

Table 1: Percentage of different group structures encountered. Total number of sightings in the wet season (Apr - Sep) 380 groups and in the dry season (Oct - Mar) 335 groups. Welch Two Sample t-test to test the differences of mean group sizes between winter and summer. Statistically significant differences are indicated in bold.

\begin{tabular}{|c|c|c|c|c|c|}
\hline \multirow[b]{2}{*}{$\begin{array}{l}\text { Group } \\
\text { composition }\end{array}$} & \multicolumn{2}{|c|}{ Summer } & \multicolumn{2}{|c|}{ Winter } & \multirow[b]{2}{*}{$\begin{array}{c}\text { Mean group size } \\
\text { comparison }\end{array}$} \\
\hline & $\begin{array}{c}\text { Encounters } \\
(\%)\end{array}$ & $\begin{array}{c}\text { Mean } \\
\text { group } \\
\text { size }\end{array}$ & $\begin{array}{c}\text { Encounters } \\
(\%)\end{array}$ & $\begin{array}{c}\text { Mean } \\
\text { group } \\
\text { size }\end{array}$ & \\
\hline $\begin{array}{l}\text { Male(s) / } \\
\text { female(s) }\end{array}$ & $\begin{array}{c}53 \\
(\mathrm{~N}=203)\end{array}$ & 9.9 & $\begin{array}{c}44 \\
(\mathrm{~N}=147)\end{array}$ & 9.5 & $\begin{array}{c}t=-0.4803, d f= \\
346.30, p=0.6313\end{array}$ \\
\hline $\begin{array}{l}\text { Multi- } \\
\text { female }\end{array}$ & $\begin{array}{c}19 \\
(\mathrm{~N}=71)\end{array}$ & 6.5 & $\begin{array}{c}21 \\
(\mathrm{~N}=69)\end{array}$ & 7.8 & $\begin{array}{c}t=-2.3982, d f= \\
137.39, p=0.018\end{array}$ \\
\hline Multimale & $\begin{array}{c}8 \\
(N=30)\end{array}$ & 4.6 & $\begin{array}{c}22 \\
(N=75)\end{array}$ & 6.7 & $\begin{array}{l}t=-3.4386, d f= \\
54.25, p=0.001\end{array}$ \\
\hline $\begin{array}{l}\text { Single } \\
\text { female }\end{array}$ & $\begin{array}{c}8 \\
(N=31)\end{array}$ & 1 & $\begin{array}{c}4 \\
(N=15)\end{array}$ & 1 & \\
\hline Single male & $\begin{array}{c}12 \\
(N=45)\end{array}$ & 1 & $\begin{array}{c}9 \\
(N=29)\end{array}$ & 1 & \\
\hline
\end{tabular}

Within the social network, female giraffes revealed strong ties over the whole year. When analysing the seasons separately, two distinct clusters could be seen in the wet season. Females show associations with certain conspecifics, but they are also highly interconnected with individuals outside their cluster (see fig. 1). All males are highly interconnected, during these summer months. 
The population appeared more divided in the dry season, with five distinct clusters emerging (see fig. 2). The strongest ties (highest HWIGs) were found between adult females, with respective associations with individuals outside their cluster being less frequent than in the wet season. During the dry season, giraffe bulls were seen comparatively more often in all male groups, forming clusters, but without showing any preferences for specific individuals as seen in females.

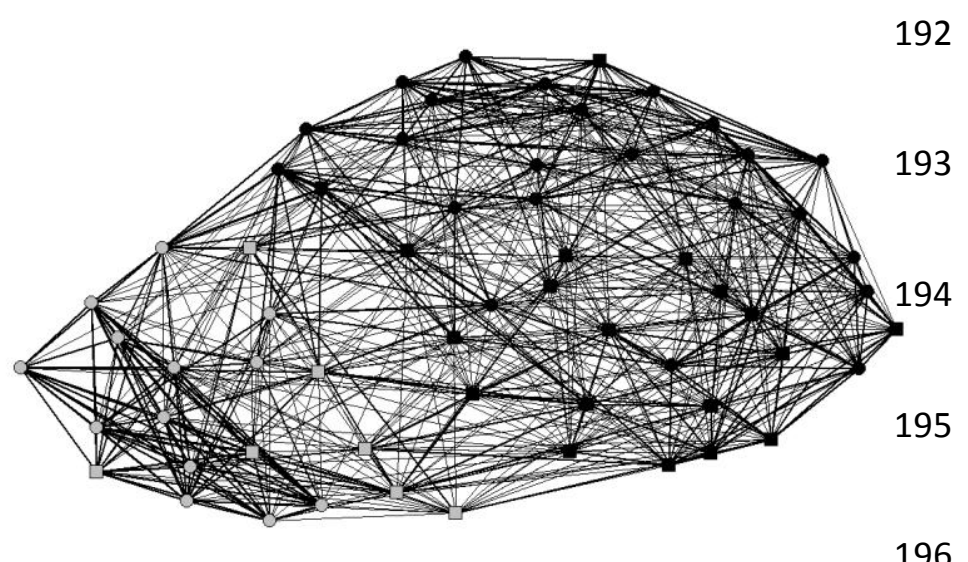

Figure 1 Cluster analysis of social networks in giraffes in the wet season (Oct - Mar) when two distinct clusters can be found. Circles $=$ female, squares $=$ male.

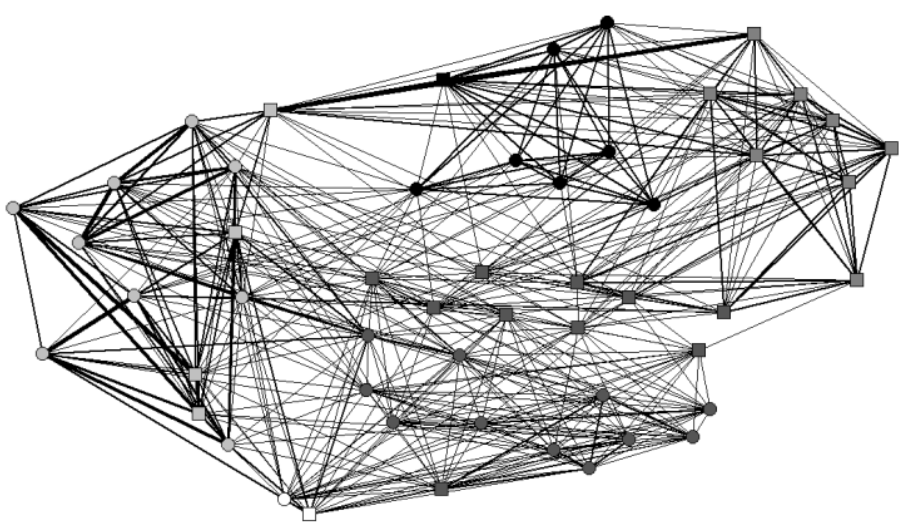

Figure 2 Cluster analysis of social networks in giraffes in the dry season (Apr - Sept) when the population is divided into five clusters. Circles $=$ female, squares $=$ male. 


\section{Discussion}

The close connectivity of individuals demonstrated within our study population is in line with the results of other studies on giraffes (Shorrocks \& Croft, 2009; Carter et al., 2013a). Given that giraffes are non-seasonal breeders and bulls regularly join female groups in search of females in oestrus, it is hardly surprising that the number of encountered mixed sex groups remained constant over the whole year. However, the group compositions changed distinctively with season and these variations appeared to differ between the sexes.

As observed in other giraffe populations (e.g. Dagg 1971; Pratt \& Anderson, 1982), a peak in parturition took place during the rainy season, and in line with this, females were encountered more often singly during this time of the year. A potential explanation for this observation is that cows temporarily separate from the group to reduce predation risk for the new-born. Giraffe females are birth 'hiders' during the first one to three weeks and females are often observed leaving their new-born babies in the nearby thicket while foraging (Langman, 1977). Although no lions are present in the reserve, hyenas and leopards might be perceived as a threat and newborns may be potential prey (Scheepers \& Gilchrist, 1991).

Overall average herd size did not differ significantly between the seasons, however, multi-female as well as multi-male groups were significantly larger during the dry season. In contrast to this, other studies found seasonal variation in overall herd sizes with larger herds during the wet season (Bercovitch \& Berry, 2010). Larger groups during the wet season may be due to a better food abundance, but especially larger multi-male groups during the dry season might be attributed to male reproductive strategies. In our study population, more fertile females can be encountered during the wet season and males might therefore spend more time 
solitary roaming between different female groups than during the dry season, were they spend more time in multi-male groups.

Our study also revealed that female giraffes associate more with one another during the rainy season. However, even though females form distinct clusters during this time of the year, they also frequently join groups outside of their core community.

Adult giraffe bulls do not show this distinct clustering during the wet period. However, sub-adult males showed strong associations with each other, as well as with adult bulls. When leaving their natal group, the young bulls started to follow more experienced adult bulls, as has been recorded in other species, such as elephants (Bowyer, 2004; Shannon et al., 2006b).

With the beginning of the dry season, the cows with newly born offspring joined the groups again, resulting in the reduced numbers of observed single females and an increase in mean group size of multi-female groups. Females with new-born calves possibly prefer joining other females with offspring, and these young giraffes are then often seen together in so called "crèches" (Langman, 1977). In the winter months, the network becomes more distinct, with more clusters found. During this time of the year, adult females show a preference for associations with other females, forming stronger bonds, and less frequently joined groups outside of their core community. These preferences could be a reflection of the bonds that have already been established during the time in the crèche (Carter et al., 2013b).

Female giraffes appear to spend more time with specific individuals during the dry season when food is scarce. These females might be genetically related to each other, as female giraffes have a tendency to associate more often with other female relatives rather than with unrelated individuals (Bercovitch \& Berry, 2013; Carter et 
al., 2013b). During times of increased feeding competition, associations with relatives may be more beneficial as it should reduce feeding competition (Silk, 2007). On the other hand, if groups become too large, competition for food between group members may increase and lead to decreased individual fitness (Clutton-Brock, Albon \& Guinness, 1982; Silk, 2007). Thus, associating with related individuals and peers from crèches would appear to be a coping strategy for females during times of reduced food abundance.

Males were more likely to be seen solitary than females (e.g. Bercovitch \& Berry, 2010; Fennessy, 2004), however, in our study population single males were encountered less often than at other study sites. Males adopt a roaming strategy to search for fertile females (Pratt \& Anderson, 1985; Cameron \& du Toit, 2005), and one possible explanation for the observed fewer solitary males might be that single males move faster when they move between female groups and this might reduce the chance of being detected by an observer. As seen in females, bulls were encountered significantly more often in multi-male groups during the dry period. Young males are reported to often associate in so called 'bachelor groups' (Dagg, 2014), however, recent findings question the existence of long-term social relationships between giraffe bulls over several seasons (Carter et al., 2013a). In these recent studies, all male groups are believed to be short-lived, providing a social unit for bulls for predator protection, to reduce feeding competition, for knowledge transfer and to practice fighting abilities (Carter et al., 2013a; Bercovitch \& Berry, 2015). In our study, adult bulls often joined young males in multi-male groups, but further studies would be needed to elucidate if those males joining a multi-male group are genetically related as it can be seen in the females. 
In conclusion, our data once more demonstrate that giraffes live in a highly flexible social system and that group composition changes frequently. We showed that not only do males and females have different association patterns, but also that group structures vary with season. One of the advantages of living in a group is predator avoidance, however, in our study population predator pressure was found to be rather low and group composition seemed to be influenced by the reproductive status of cows. Social factors might play a greater role in giraffe grouping behaviour than predator pressure, which would be in line with the finding that giraffes seem to allocate a significant portion of their vigilant behaviour towards conspecifics (Cameron \& du Toit, 2005). However, it should be noted that past and present findings are of course based on observations from a human perspective, and that the social environment might be perceived in a completely different way by giraffes due to respective differences in anatomy and acoustic as well as olfactory and visual abilities. Further innovative research will thus be needed to fully understand the flexible behaviour seen in this iconic species.

\section{Acknowledgments}

We would like to thank the Pongola Game Reserve for their support, especially $\mathrm{H}$. Zitzer for her help and assistance. We are also grateful to two anonymous reviewers for comments on the manuscript.

Financial support was provided by the National Research Foundation, South Africa and a postgraduate bursary from the DST-NRF SARChl chair for Mammal behavioural ecology and physiology to (NCB). 


\section{References}

Alexander, R.D. (1974). The Evolution of Social Behavior. Annu. Rev. Ecol. Syst. 5, 325-383.

Aureli, F., Schaffner, C.M., Boesch, C., Bearder, S.K., Call, J., Chapman, C.A., Connor, R., Fiore, A.D., Dunbar, R.I.M., Henzi, S.P., Holekamp, K., Korstjens, A.H., Layton, R., Lee, P., Lehmann, J., Manson, J.H., Ramos-Fernandez, G., Strier, K.B., van Schaik, C.P. (2008). Fission-Fusion Dynamics: New Research Frameworks. Curr. Anthropol. 49, 627-654.

Bercovitch, F.B., Berry, P.S.M. (2009). Reproductive life history of Thornicroft's giraffe in Zambia. Afr. J. Ecol. 48, 535-538.

Bercovitch, F.B., Berry, P.S.M. (2010). Ecological determinants of herd size in the Thornicroft's giraffe of Zambia. Afr. J. Ecol. 48, 962-971.

Bercovitch, F.B., Berry, P.S.M. (2013). Herd composition, kinship and fission-fusion social dynamics among wild giraffe. Afr. J. Ecol. 51, 206-216.

Bercovitch, F.B., Berry, P.S.M. (2015). The composition and function of all-male herds of Thornicroft's giraffe, Giraffa camelopardalis thornicrofti, in Zambia. Afr. J. Ecol. 53, 167-174.

Bowyer, R.T. (2004). Sexual segregation in ruminants: definitions, hypotheses, and implications for conservation and management. J. Mammal. 85, 1039-1052.

Cairns, S.J., Schwager, S.J. (1987). A comparison of association indices. Anim. Behav. 35, 1454-1469.

Cameron, E.Z., du Toit, J.T. (2005). Social influences on vigilance behaviour in giraffes, Giraffa camelopardalis. Anim. Behav. 69, 1337-1344. 
Carter, K.D., Brand, R., Carter, J.K., Shorrocks, B., Goldizen, A.W. (2013a). Social networks, long-term associations and age-related sociability of wild giraffes. Anim. Behav. 86, 901-910.

Carter, K.D., Seddon, J.M., Frère, C.H., Carter, J.K., Goldizen, A.W. (2013b). Fission-fusion dynamics in wild giraffes may be driven by kinship, spatial overlap and individual social preferences. Anim. Behav. 85, 385-394.

Clutton-Brock, T.H., Albon, S.D., Guinness, F.E. (1982). Competition between female relatives in a matrilocal mammal. Nature $300,178-180$.

Cross, P.C., Lloyd-Smith, J.O., Getz, W.M. (2005). Disentangling association patterns in fission-fusion societies using African buffalo as an example. Anim. Behav. 69, 499-506.

Dagg, A.I. (1971). Giraffa camelopardalis. Mamm. Species 5, 1-8.

Dagg, A.I. (2014). Giraffe: biology, behaviour, and conservation. New York: Cambridge University Press.

Fennessy, J.T. (2004). Ecology of desert-dwelling giraffe Giraffa camelopardalis angolensis in northwestern Namibia. PhD Thesis, University of Sydney.

Frère, C.H., Krützen, M., Mann, J., Watson-Capps, J.J., Tsai, Y.J., Patterson, E.M., Connor, R., Bejder, L., Sherwin, W.B. (2010). Home range overlap, matrilineal and biparental kinship drive female associations in bottlenose dolphins. Anim. Behav. 80, 481-486.

Godde, S., Humbert, L., Côté, S.D., Réale, D., Whitehead, H. (2013). Correcting for the impact of gregariousness in social network analyses. Anim. Behav. 85, $553-558$.

Godde, S., Côté, S.D., Réale, D. (2015). Female mountain goats, Oreamnos americanus, associate according to kinship and reproductive status. Anim. Behav. 108, 101-107. 
Langman, V.A. (1977). Cow-calf Relationships in Giraffe (Giraffa camelopardalis giraffa). Z. Für Tierpsychol. 43, 264-286.

Ngonga Ngomo, A.-C., Schumacher, F. (2009). BorderFlow: A Local Graph Clustering Algorithm for Natural Language Processing. In Computational Linguistics and Intelligent Text Processing: 547-558. Gelbukh, A. (Ed.). Berlin, Heidelberg: Springer.

Pratt, D.M., Anderson, V.H. (1982). Population, distribution, and behaviour of giraffe in the Arusha National Park, Tanzania. J. Nat. Hist. 16, 481-489.

Pratt, D.M., Anderson, V.H. (1985). Giraffe social behaviour. J. Nat. Hist. 19, 771781.

R Core Team (2013). R: A language and environment for statistical computing. Vienna, Austria.

Rubenstein, D.I. (1986). Ecology and Sociality in Horses and Zebras. In Ecological Aspects of Social Evolution: 282-302 Rubenstein, D. I., \& Wrangham, R. W. (Eds.). Princeton: Princeton University Press.

Scheepers, J.L., Gilchrist, D. (1991). Leopard predation on giraffe calves in the Etosha National Park. Madoqua 18, 49.

Shannon, G., Page, B., Slotow, R., Duffy, K. (2006a). African elephant home range and habitat selection in Pongola Game Reserve, South Africa. Afr. Zool. 41, 37-44.

Shannon, G., Page, B.R., Duffy, K.J., Slotow, R. (2006b). The role of foraging behaviour in the sexual segregation of the African elephant. Oecologia 150, 344-354.

Shorrocks, B., Croft, D.P. (2009). Necks and networks: a preliminary study of population structure in the reticulated giraffe (Giraffa camelopardalis reticulata de Winston). Afr. J. Ecol. 47, 374-381. 
Silk, J.B. (2007). The adaptive value of sociality in mammalian groups. Philos. Trans. R. Soc. B Biol. Sci. 362, 539-559.

Sundaresan, S.R., Fischhoff, I.R., Dushoff, J., Rubenstein, D.I. (2007). Network metrics reveal differences in social organization between two fission-fusion species, Grevy's zebra and onager. Oecologia 151, 140-149.

Van der Waal, K.L., Wang, H., McCowan, B., Fushing, H., Isbell, L.A. (2014). Multilevel social organization and space use in reticulated giraffe (Giraffa camelopardalis). Behav. Ecol. 25, 17-26.

Whitehead, H. (2009). SOCPROG programs: analysing animal social structures. Behav. Ecol. Sociobiol. 63, 765-778.

Whitehead, H., Dufault, S. (1999). Techniques for Analyzing Vertebrate Social Structure Using Identified Individuals: Review and Recommendations. In Advances in the Study of Behavior: 33-74. Slater, P.J.B; Rosenblat, J.S.; Snowden, C.T; Roper, T.J. (eds.). San Diego: Academic Press. 